\title{
Macrophages may promote cancer growth via a GM-CSF/HB-EGF paracrine loop that is enhanced by CXCL12
}

Antonella Rigo ${ }^{1 \dagger}$, Michele Gottardi ${ }^{1 \dagger}$, Alberto Zamò ${ }^{2}$, Pierluigi Mauri ${ }^{3}$, Massimiliano Bonifacio ${ }^{1}$, Mauro Krampera ${ }^{1}$, Ernesto Damiani ${ }^{4}$, Giovanni Pizzolo', Fabrizio Vinante ${ }^{1 *}$

\begin{abstract}
Background: Increased numbers of tumour-associated macrophages correlate with shortened survival in some cancers. The molecular bases of this correlation are not thoroughly understood. Events triggered by CXCL12 may play a part, as CXCL12 drives the migration of both CXCR4-positive cancer cells and macrophages and may promote a molecular crosstalk between them.
\end{abstract}

Results: Samples of HER1-positive colon cancer metastases in liver, a tissue with high expression of CXCL12, were analysed by immunohistochemistry. In all of the patient biopsies, CD68-positive tumour-associated macrophages presented a mixed CXCL10 (M1)/CD163 (M2) pattern, expressed CXCR4, GM-CSF and HB-EGF, and some stained positive for CXCL12. Cancer cells stained positive for CXCR4, CXCL12, HER1, HER4 and GM-CSF. Regulatory interactions among these proteins were validated via experiments in vitro involving crosstalk between human mononuclear phagocytes and the cell lines DLD-1 (human colon adenocarcinoma) and HeLa (human cervical carcinoma), which express the above-mentioned ligand/receptor repertoire. CXCL12 induced mononuclear phagocytes to release HB-EGF, which activated HER1 and triggered anti-apoptotic and proliferative signals in cancer cells. The cancer cells then proliferated and released GM-CSF, which in turn activated mononuclear phagocytes and induced them to release more HB-EGF. Blockade of GM-CSF with neutralising antibodies or siRNA suppressed this loop.

Conclusions: CXCL12-driven stimulation of cancer cells and macrophages may elicit and reinforce a GM-CSF/HBEGF paracrine loop, whereby macrophages contribute to cancer survival and expansion. The involvement of mixed M1/M2 GM-CSF-stimulated macrophages in a tumour-promoting loop may challenge the paradigm of tumourfavouring macrophages as polarized M2 mononuclear phagocytes.

\section{Background}

Over the last few years, a great deal of attention has been paid to the clinical significance of macrophages that infiltrate cancer. A number of studies provide evidence that tumour-associated macrophages are a negative prognostic factor of survival $[1,2]$. A recent geneprofiling study demonstrates that the overexpression of a macrophage signature and an increased number of tumour-infiltrating macrophages in diagnostic lymph-

\footnotetext{
* Correspondence: fabrizio.vinante@univr.it

+ Contributed equally

'Department of Medicine, Section of Hematology, University of Verona, Verona, Italy

Full list of author information is available at the end of the article
}

nodes are associated with poor outcome in classic Hodgkin's lymphoma patients [3]. Other studies underline pathways leading to M2 macrophage responses that foster tumour growth [4-7]. In the end, all these studies deal with the crosstalk between tumour cells and macrophages. For instance, a regulatory loop between breast cancer cells and macrophages has been described [8], and the cellular expression of matrix metallopeptidase 11 seems to be relevant to disease outcome at least in classic Hodgkin's lymphoma [3]. However, the grounds on which the above-mentioned prognostic significance rests are not so thoroughly appreciated, especially in terms of cell-to-cell molecular mechanisms.
C Biomed Central

C 2010 Rigo et al; licensee BioMed Central Ltd. This is an Open Access article distributed under the terms of the Creative Commons Attribution License (http://creativecommons.org/licenses/by/2.0), which permits unrestricted use, distribution, and reproduction in any medium, provided the original work is properly cited. 
Within the tangle of relations between macrophages and cancer cells, we tried to tease out the role that CXCL12 plays in both cancer cells and macrophages at the boundaries between cancer and inflammation. A tissue with high expression of CXCL12 (for example, liver or bone marrow) may represent a site that preferentially attracts both macrophages [9] and cancer cells $[10,11]$, which co-migrate depending on their expression of the CXCL12 receptors CXCR4 and/or CXCR7 [12]. Ligand binding to these receptors, which are heterotrimeric guanine nucleotide-binding proteincoupled receptors (GPCR), activates matrix metallopeptidases that cleave EGF-family ligands, such as EGF or HB-EGF, from the cell membrane [13], leading to transactivation of HER1 on neighbouring cells [14]. This transactivation mechanism is a general function of GPCR signalling [15]. HER1 expressed by epithelial cancers plays a pivotal role by transducing signals that favour tumour progression [16,17]. The macrophageregulator GM-CSF, which is produced by some types of cancer cells $[18,19]$, specifically induces HB-EGF in macrophages and neutrophils [20].

Because mononuclear phagocytes express both CXCL12 GPCRs and HB-EGF, we argued that the recruitment of mononuclear phagocytes to a site of metastasis such as liver through CXCL12 should induce a release of HB-EGF, which is expected to activate HER1 and favour tumour progression. We found that tumour-associated macrophages and metastatic HER1positive colon cancer in liver biopsies expressed a ligand/receptor repertoire that was consistent with our hypothesis and that in vitro CXCL12 could trigger a GM-CSF/HB-EGF paracrine loop whereby mononuclear phagocytes support cancer survival.

\section{Methods}

\section{Ethical requirements}

The blood and histological samples used in our study were in compliance with Institutional Review Board regulations.

\section{Cells and reagents}

Highly purified human mononuclear phagocytes and neutrophils were isolated from the buffy coats [21] of blood samples from healthy volunteers. HeLa (human cervical carcinoma), DLD-1 (human colon adenocarcinoma) and Balb/c 3T3 (Swiss mouse embryo) cell lines (purchased from ATCC, Manassas, VA) and HUVEC (human umbilical vein endothelial cells, purchased from Cambrex, Walkersville, VA) were also used. Non-adherent and adherent cells were grown in RPMI-1640 medium and DMEM or TC199 + 10\% FCS (complete medium; Invitrogen, Carlsbad, CA), respectively. Cells were treated with $200 \mathrm{ng} / \mathrm{mL}$ CXCL12 (Peprotech,
London, UK) or $25 \mathrm{ng} / \mathrm{mL}$ GM-CSF (Genetics Institute, Boston, MA) or $25 \mathrm{ng} / \mathrm{mL}$ HB-EGF or $100 \mu \mathrm{g} / \mathrm{mL}$ antiHB-EGF or $100 \mu \mathrm{g} / \mathrm{mL}$ anti-GM-CSF neutralising monoclonal antibody (mAb) (R\&D Systems, Minneapolis, $\mathrm{MN}$ ) or isotypic control immunoglobulins. After growing in cultures for the appropriate times in different conditions, the cells were either lysed for total RNA extraction or used for functional assays. In some experiments, the conditioned medium was replaced with fresh medium after 24 hours of stimulation and the cells were then maintained in culture for up to 48 hours. Cell-free supernatants $(\mathrm{SN})$ were stored at $-80^{\circ} \mathrm{C}$.

\section{Immunochemistry on tissues and cells}

Histological samples were obtained by hepatic lobectomy to excise metastatic nodules derived from colon cancer. After surgical excision, samples were put in buffered formalin, treated in an automated processor and embedded in paraffin. Four micrometre-thick slices were cut from paraffin blocks onto adhesive-coated slides. Cytological samples were obtained by allowing cells to grow on the slides. Antibodies (Ab) used included the following: CD163 (clone 10D6, 1/200; Novocastra, Newcastle-upon-Tyne, UK), CXCL10 and CXCR4 (both rabbit polyclonal, 1/500 and 1/100, respectively; Abcam, Cambridge, UK), CXCL12 (clone 7918, 1/100), GM-CSF (clone 3209, 1/100), HER1 (1/100), HER4 (1/100), and HB-EGF (clone 125923, 1/200) (all purchased from R\&D Systems). Antigen retrieval was performed for all antibodies in a hot bath for 30 minutes at pH 6 (except for GM-CSF retrieval, which was performed at $\mathrm{pH} 8$ ). For GM-CSF and HB-EGF no $\mathrm{H}_{2} \mathrm{O}_{2}$ blocking was performed. As controls, sequential sections or cytological slides were incubated with the Ab diluent and indifferent isotypic $\mathrm{Ab}$. All procedures were performed on an automated stainer (Bond, Vision Biosystems, Melbourne, AU) using a polymer detection system (NovoLink, Novocastra).

\section{Flow cytometry}

Following stimulation for 20 minutes or 24 hours with CXCL12, $1 \times 10^{6}$ cells were incubated with a goat antihuman HB-EGF IgG polyclonal Ab (Oncogene, San Diego, CA) or an IgG control Ab. After washing, $5 \mu \mathrm{L}$ of phycoerythrin-conjugated swine anti-goat IgG (Caltag Laboratories, Burlingame, CA) was added. The cells were then analysed on a FACSCalibur (Becton-Dickinson, Mountain View, CA) using the FlowJo 8.8.2 program (Tree Star, Ashland, OR).

\section{HER1 transactivation assay}

Cellular release of HB-EGF was evaluated by measuring its effect on HER1 phosphorylation at tyrosine 1068 (Y1068) using HeLa and DLD-1 as target cells. 
Approximately $3 \times 10^{6}$ effector cells (mononuclear phagocytes and neutrophils) were seeded in the upper chamber of a $0.4 \mu \mathrm{m}$ transwell co-culture system (Costar, Cambridge, MA) and were stimulated with CXCL12 for 20 minutes. In a separate experiment, $3 \times 10^{6}$ mononuclear phagocytes and neutrophils were cultured in the presence or absence of CXCL12 for 24 hours and their conditioned medium was added to the target cells for 20 minutes. HeLa cells were also stimulated for 20 minutes with recombinant human HB-EGF. Subconfluent HeLa cells that had been starved for 24 hours were incubated in the presence or absence of the anti-HB-EGF neutralising Ab (R\&D Systems). Target cells were harvested for protein extraction.

\section{Protein extraction}

Cell pellets were lysed for 30 minutes in $1 \mathrm{~mL}$ ice-cold cell extraction buffer (Biosource, Camarillo, CA), which was supplemented with a protease inhibitor cocktail (Sigma, St. Louis, MO) and $1 \mathrm{mM}$ PMSF (Sigma). After centrifugation at $13,000 \mathrm{rpm}$ for 10 minutes at $4^{\circ} \mathrm{C}$, aliquots of the $\mathrm{SN}$ were stored at $-80^{\circ} \mathrm{C}$.

\section{Mass spectrometry}

Approximately $1 \times 10^{7} \mathrm{HeLa}$ cells, which were either untreated or treated with HB-EGF for 20 minutes, were harvested for HER1 immunoprecipitation, reduction, alkylation and tryptic digestion. Ten microliters of the peptide mixture was analysed by means of an LCMS/ MS system [22]. The data handling for the identification of phosphorylated residues was performed according to Guo et al. [23]. HB-EGF-induced HER1 phosphorylation was evaluated at Y992, Y1045, Y1068, Y1086, S1142, Y1148, Y1173, and expressed as phosphorylation ratio (phosphorylation after stimulus/basal phosphorylation).

\section{ELISA}

1. HER1 $p Y 1068$ and ERK1/2 pTpY185/187. Total HER1 versus HER1 pY1068 and total ERK1/2 versus ERK1/2 pTpY-185/187 were measured in cell protein extracts using a commercially available ELISA (Biosource). The results were calculated as the ratio of phosphorylated molecules to total molecules and expressed as the percentage of phosphorylation. 2. HB-EGF and GM-CSF. The cell-free culture SN was assayed for soluble HB-EGF protein using a specific ELISA developed in our laboratory [20] and for GM-CSF using a commercial ELISA (R\&D Systems). Only SN previously purified from HBEGF or GM-CSF by specific crosslinking (Invitrogen) were subsequently used as agonistic SN to induce HBEGF or GM-CSF, respectively, in cell stimulation experiments followed by ELISA tests. 3. Apoptosis. 72-hour internucleosomal DNA fragmentation as an index of apoptosis was evaluated using a cell death detection
ELISA (Roche Diagnostics, Mannheim, DE) and expressed as the mean \pm SD of triplicate determinations of the enrichment factor (absorbance of unstimulated cells/absorbance of stimulated cells).

\section{Northern blotting}

Total RNA was extracted from the indicated cells. Northern blot analysis (with $10 \mu \mathrm{g}$ RNA/lane) was performed as described [19]. Filters were hybridised with ${ }^{32}$ P-labelled cDNA probes complementary to the HBEGF RNA sequence, which were generated in our laboratory or with a ${ }^{32} \mathrm{P}$-labelled plasmid containing a cDNA probe that detected the $\beta$-actin RNA sequence.

\section{RT-PCR}

Total cellular RNA was purified by the QIAamp RNA Blood mini kit (Qiagen, Hilden, DE) + DNase digestion (Qiagen). Templates were generated from $2 \mu \mathrm{g}$ of RNA with the Superscript III First-Strand Synthesis System kit (Invitrogen). cDNA for GM-CSF was amplified using the following primers (Invitrogen): 5'-CTCAGAAATGTTTGACCTCCAG-3' (sense) and 5'-TGACAAGCAGAAAGTCCTTCAG-3' (antisense) for a 221 bp amplicon. The GAPDH internal control primers (SuperArray Bioscience, Frederick, MD) were used to co-amplify a specific fragment that was $436 \mathrm{bp}$ long. After 30 cycles at $95^{\circ} \mathrm{C}$ for $15^{\prime \prime}, 55^{\circ} \mathrm{C}$ for $30^{\prime \prime}$ and $72^{\circ} \mathrm{C}$ for $30^{\prime \prime}$ in a Veriti thermal cycler (Applied Biosystems, Foster City, CA) using the AmpliTaq Gold PCR master mix (Applied Biosystems), the reactions were analysed by agarose gel electrophoresis and recorded using a VersaDoc imaging system (Bio-Rad, Hercules, CA).

\section{Cell proliferation and apoptosis}

Hela, DLD-1, HUVEC and Balb/c 3T3 cells were seeded in 96-well plates in complete medium and allowed to adhere for 24 hours. They were then incubated in the absence or presence of the anti-HB-EGF neutralizing $\mathrm{Ab}$ (R\&D Systems) and were stimulated with $25 \mathrm{ng} / \mathrm{mL} \mathrm{HB-}$ EGF. In selected experiments, HeLa and DLD-1 were deprived of serum and cultured in the absence or presence of HB-EGF. Cell proliferation was measured by MTT incorporation [19] at 24, 48 and 72 hours and expressed as the proliferation index. Apoptosis was measurerd as the internucleosomal DNA fragmentation enrichment factor at 72 hours (see ELISA).

\section{siRNA knockdown}

To silence the expression of GM-CSF, HeLa and DLD-1 cells were seeded on glass slides $\left(10^{5}\right.$ cells $\left./ \mathrm{mL}\right)$, stimulated with $200 \mathrm{ng} / \mathrm{mL}$ CXCL12 and/or $25 \mathrm{ng} / \mathrm{mL}$ HB-EGF or SN from GM-CSF-stimulated mononuclear phagocytes and transfected 48 hours using HiPerFect Transfection Reagent and siRNA (2 $\mathrm{nM}$ and $5 \mathrm{nM}$ 
respectively, GM-CSF siRNA no. SI03037272 and AllStars negative control siRNA - Alexa Fluor 488; Qiagen). Transfection efficiency (> 95\%) was determined by flow cytometry on trypsinized cells. Effective silencing of GM-CSF was determined by testing the induction and release of 1. GM-CSF in cancer cells (using immunohistochemistry and ELISA, after a 24-hour stimulation with HB-EGF or mononuclear phagocytes conditioned medium) and 2. HB-EGF in mononuclear phagocytes (using flow cytometry and ELISA, after a 24-hour stimulation with silenced cancer cell SN).

\section{Statistics}

Student's $t$-test, Mann-Whitney U test and KruskallWallis ANOVA by ranks were used. Differences were considered significant for $p$ values $<0.05$.

\section{Results}

Macrophages infiltrate colon cancer metastases in liver

We analysed the histological pattern of surgical samples from 15 patients aged 60 to 79 who underwent hepatic lobectomy in order to excise metastatic colon cancer nodules. In Figure 1, we show the representative histology from a 76-year-old patient who had such a procedure. Serial preparations of a subglissonian metastatic nodule were stained by immunohistochemistry for CD68, CXCL10, CD163, CXCR4, CXCL12, GM-CSF, HER1, HER4 and HB-EGF. Macrophages, which were found to infiltrate the metastatic region often creating a bridge between perivascular zones and metastases, were intensely positive for CD68, CXCR4, GM-CSF and HBEGF; some were CXCL12-positive. Of interest, macrophages stained positive for both CXCL10 (M1-marker) and CD163 (M2-marker). Though we could not perform a double staining, the distribution of the expression of CXCL10 and CD163 suggests a cellular co-expression rather than distinct populations of cells. In any case, the macrophages were not definitely polarized towards a typical M2 pattern but instead showed a mixed M1/M2 pattern. The cancer cells were positive for CXCR4, CXCL12, HER1, HER4 (a chemotactic receptor that responds to HB-EGF), and GM-CSF. The cellular distribution of ligands and receptors suggested specific interplays that were tested in the following experiments performed on the HeLa and DLD-1 cancer cell lines, which express the same pattern of molecules, and on human mononuclear phagocytes ex vivo.

\section{CXCL12 induces HB-EGF synthesis and release in mononuclear phagocytes}

Under basal conditions, mononuclear phagocytes express HB-EGF (Figure 2A, B). When we stimulated mononuclear phagocytes with $200 \mathrm{ng} / \mathrm{mL}$ CXCL12, the membrane density of HB-EGF was initially reduced (at
20 minutes), but was increased after 24 hours (Figure 2A). After a 2-hour stimulation, constitutive HB-EGF mRNA transcripts were up-regulated in mononuclear phagocytes (Figure 2B), and this effect increased up to 24 hours (data not shown). This induction of HBEGF was cell type specific. For instance, we show in Figure $2 \mathrm{~B}$ that neutrophils did not express HB-EGF transcripts either basally or after CXCL12 stimulation. A 1hour stimulation of mononuclear phagocytes with CXCL12 determined an increase in the HB-EGF concentration in the culture supernatants (Figure 2C). Thus, CXCL12-dependent signals induce mononuclear phagocytes to release HB-EGF from the cell membrane, increase the amounts of HB-EGF transcripts at 2 hours, and upregulate HB-EGF synthesis, leading to an increase in membrane-bound HB-EGF at 24 hours.

\section{HB-EGF-dependent HER1 phosphorylation}

To test if the stimulation of mononuclear phagocytes with CXCL12 could induce HER1 transactivation in bystander cells via HB-EGF shedding, we performed transwell co-cultures, in which we analysed HER1 phosphorylation at tyrosine 1068. Tyrosine 1068, a major site of autophosphorylation that is associated with the activation of Ras, MEK and ERK1/2 [24] was chosen after performing mass spectrometry analysis of liganddependent HER1 phosphorylation in HeLa cells. Mass spectrometry confirmed that $25 \mathrm{ng} / \mathrm{mL}$ HB-EGF induced a phosphorylation pattern different from that induced by other HER1 ligands [23,24] and that Y1068 phosphorylation was induced by HB-EGF in either HeLa or DLD-1 cells (Figure 3A). Moreover, HB-EGF-dependent phosphorylation was coupled to phosphorylation of ERK1/2 at threonine 185 and tyrosine 187 (Figure 3B), as expected [24].

\section{CXCL12-driven release of HB-EGF from mononuclear phagocytes transactivates HER1 and supports proliferative, anti-apoptotic and angiogenic effects in bystander cells}

To determine if CXCL12 induces the transactivation of HER1, we performed the transwell experiments depicted in Figure 4. Mononuclear phagocytes (and neutrophils as negative control) in the upper chamber were stimulated with $200 \mathrm{ng} / \mathrm{mL}$ CXCL12 and HER1-positive HeLa, DLD-1, Balb/c 3T3 cells and HUVEC were used in the lower chamber as target cells. After 20 minutes, the cells were analysed to assess HER1 phosphorylation at tyrosine 1068 . Figure $4 \mathrm{~A}$ depicts several negative controls. The direct stimulation of HeLa, DLD-1, Balb/c 3T3 cells and HUVEC with CXCL12 did not induce HER1 phosphorylation. Unstimulated mononuclear phagocytes did not induce HER1 phosphorylation in the target cells. Neutrophils, which do not express HB-EGF 







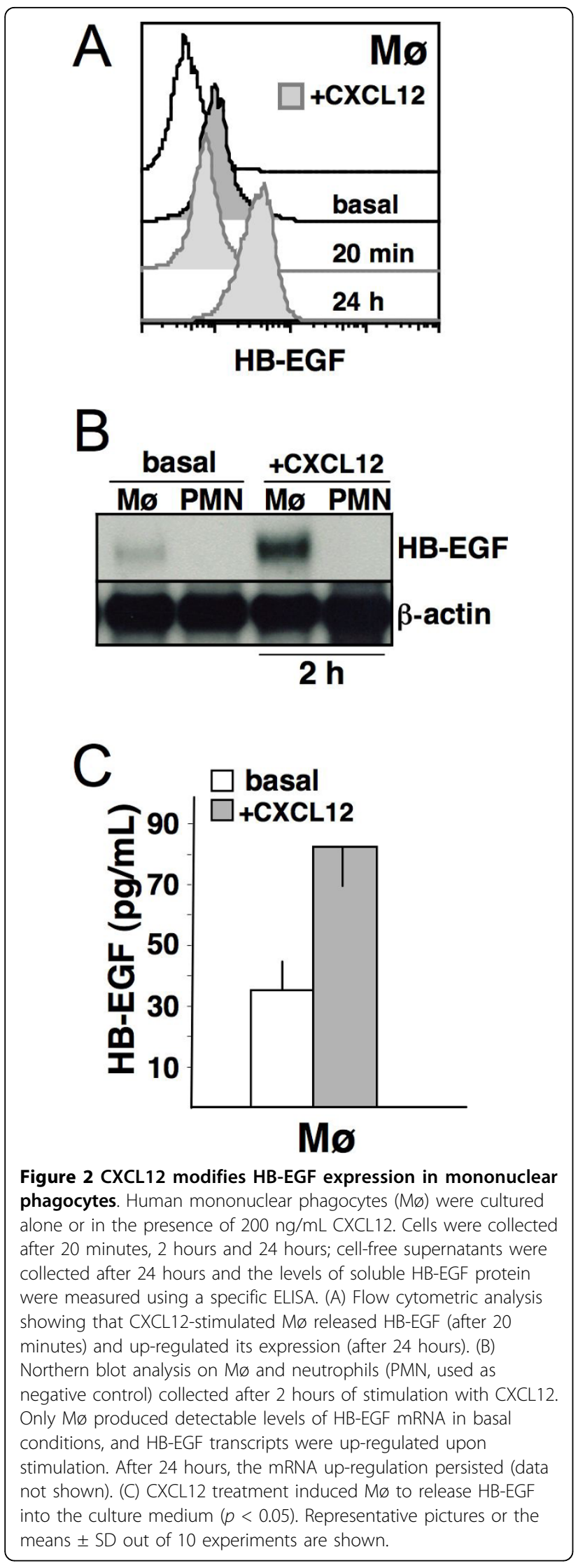

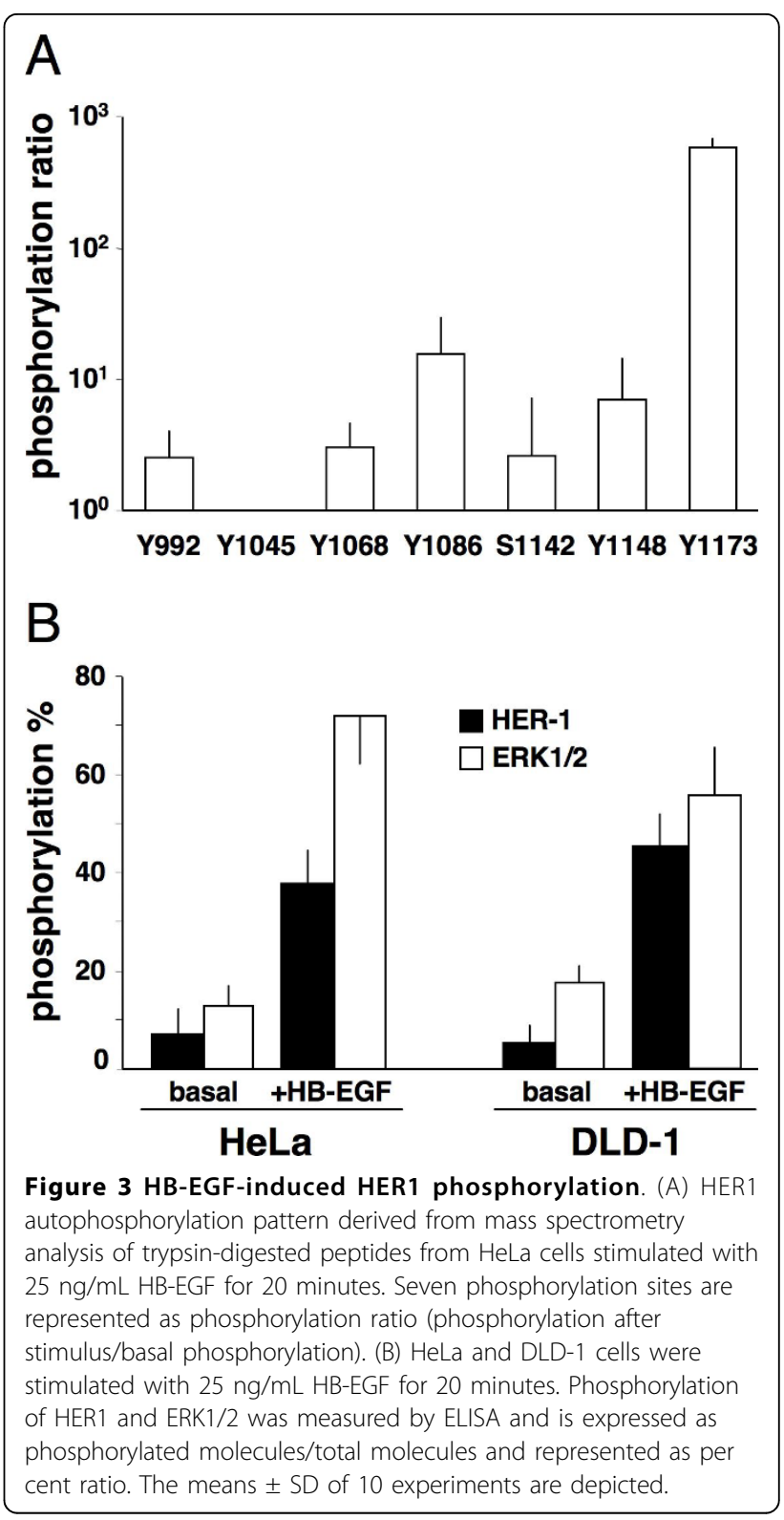

[20], were treated with CXCL12 and this treatment did not lead to phosphorylation of HER1 at tyrosine 1068 in the target cells. In contrast, as depicted in Figure 4B, treatment of mononuclear phagocytes with CXCL12 led to the strong phosphorylation of Y1068 in all of the target cells. Pre-treatment with $100 \mu \mathrm{g} / \mathrm{mL}$ of neutralising anti-HB-EGF, but not its corresponding controls, inhibited the transactivation of HER1. Finally, supernatants from CXCL12-stimulated neutrophils, which did not produce HB-EGF, were not effective (SN1, Figure 5A, B, C). Mononuclear phagocytes-derived supernatants (SN2, Figure 5A) contained factors that led to HER1 phosphorylation in, and proliferation of, HeLa and DLD-1 cells (Figure 5B, C) as well as HUVEC and Balb/c 3T3 

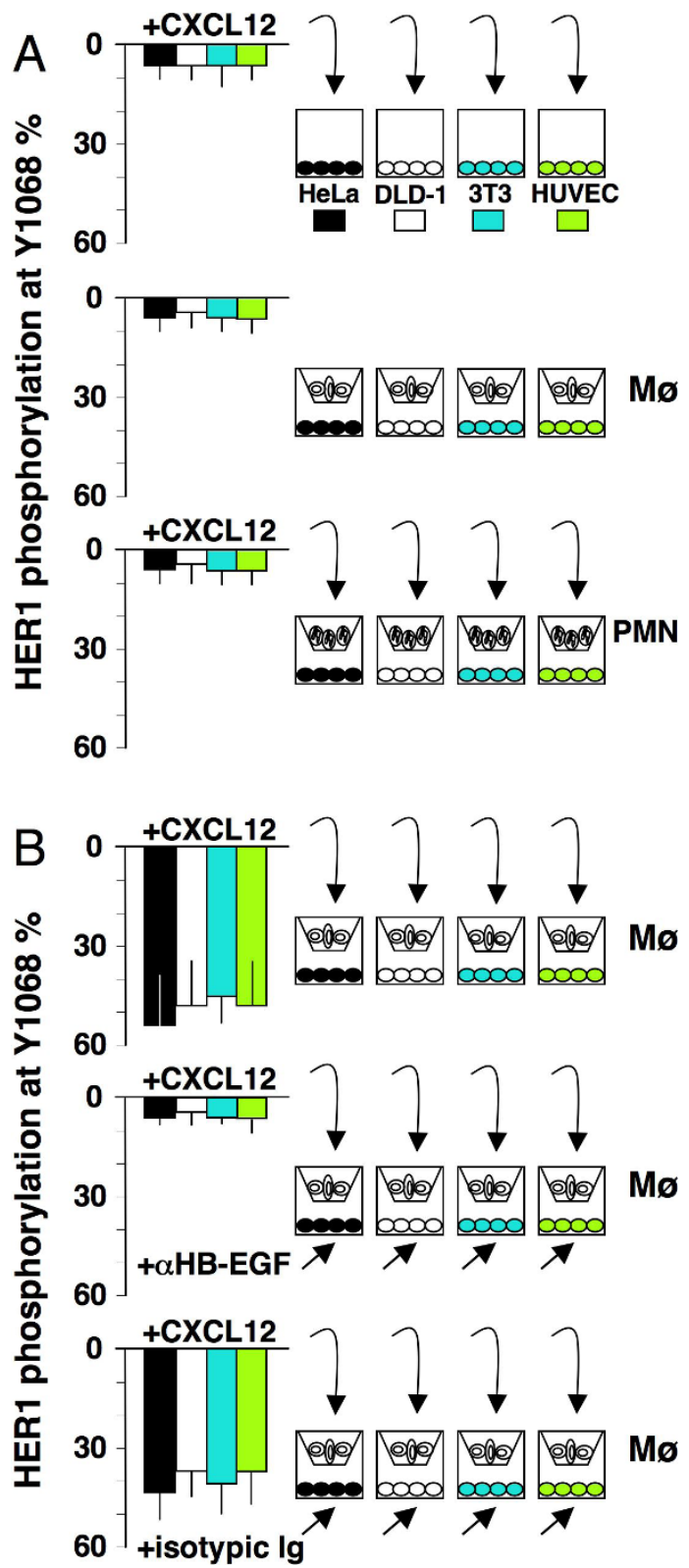

Figure 4 CXCL12-dependent transactivation of HER1 in transwell experiments. Human mononuclear phagocytes $(M \varnothing)$ and neutrophils (PMN, used as negative control) were stimulated with $200 \mathrm{ng} / \mathrm{mL}$ CXCL12 in the upper chamber of a transwell containing HeLa, DLD-1, Balb/c 3T3 or HUVEC target cells in the lower chamber. HeLa, DLD-1, Balb/c 3T3 and HUVEC were collected after 20 minutes of stimulation, and HER1 phosphorylation at $\mathrm{Y} 1068$ was measured by an ELISA using specific anti-tyrosine mAbs, expressed as phosphorylated molecules/total molecules and represented as a per cent ratio. (A) Negative controls: CXCL12 alone, stimulated PMN or unstimulated $M \varnothing$ were ineffectual. (B) Effect of Mø stimulation: CXCL12 led to HER1 transactivation in either HeLa, DLD-1, Balb/c 3 T3 or HUVEC $(p<0.05)$. Pre-treatment with $100 \mu \mathrm{g} / \mathrm{mL}$ anti-HB-EGF neutralising Ab abolished $\mathrm{Y} 1068$ phosphorylation in the target cells $(p<0.05)$. The isotypic control of neutralising anti-HB-EGF mAb was not effective. The colour pattern of the bars refers to each type of target cell. The means \pm SD of 10 experiments are depicted.

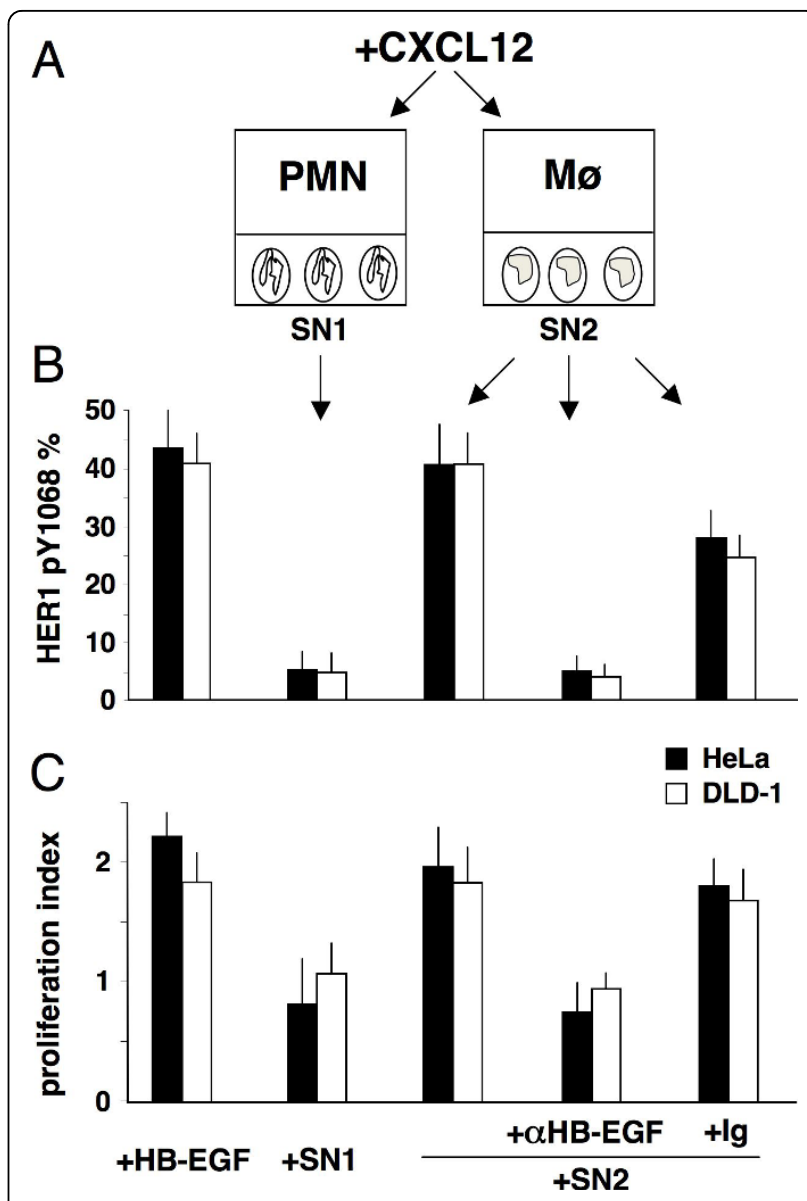

Figure 5 Proliferation induced by supernatants from CXCL12stimulated mononuclear phagocytes. (A) Human mononuclear phagocytes (Mø) or neutrophils (PMN) were stimulated with 200 $\mathrm{ng} / \mathrm{mL}$ CXCL12 and cell free supernatants were collected after 24 hours and added to either HeLa or DLD-1 cells. (B) Supernatants from CXCL12-stimulated PMN (SN1) were not effective at inducing phosphorylation of HER1, because PMN did not produce HB-EGF. Supernatants from CXCL12-stimulated Mø (SN2) induced HER1 phosphorylation at Y1068 when added to HeLa or DLD-1 cells $(p<$ 0.05). The phosphorylation was genuinely inhibited by $100 \mu \mathrm{g} / \mathrm{mL}$ anti-HB-EGF neutralising Abs. (C) SN2 caused HeLa and DLD-1 cells to proliferate to a degree that was comparable to stimulation with $25 \mathrm{ng} / \mathrm{mL} \mathrm{HB}$-EGF. The means \pm SD of 10 experiments are depicted.

cell proliferation (SN2, Figure 6A). Blockade of HB-EGF with the neutralising $\mathrm{Ab}$ abolished the phosphorylation and the proliferation of the cells (Figures 4B; 5B, C; 6A). However, this effect did not occur when using indifferent isotypic immunoglobulins. Thus, CXCL12 induced the release of functional HB-EGF from mononuclear phagocytes, transactivation of HER1 and proliferation of cancer cells (HeLa and DLD-1), fibroblasts (Balb/c 3T3 cells) and endothelial cells (HUVEC). This occurred both in transwell co-cultures and after adding conditioned medium (from cultures of mononuclear phagocytes stimulated with CXCL12) to the target cells. 

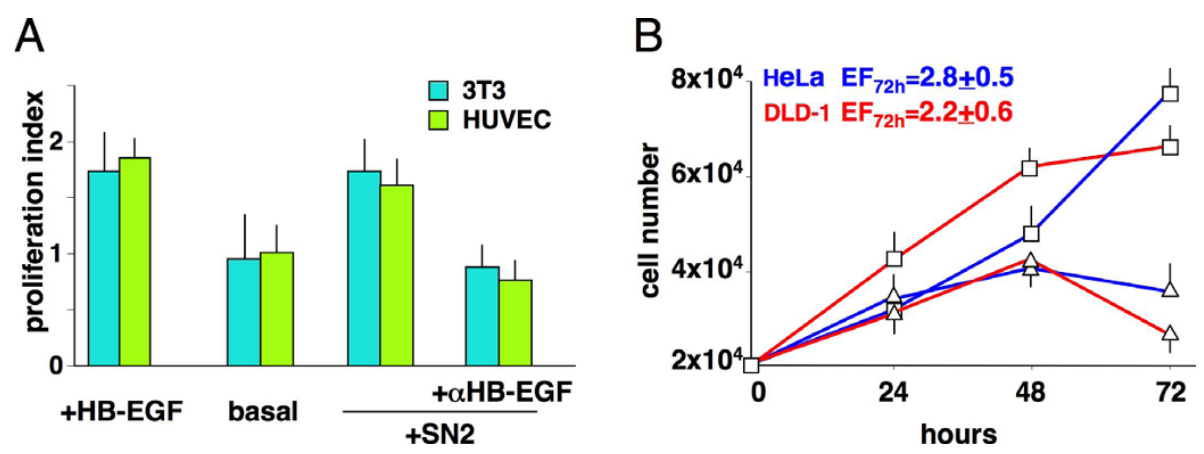

Figure 6 Angiogenic, proliferative and anti-apoptotic activities of HB-EGF. (A) HB-EGF or supernatants from CXCL12-stimulated mononuclear phagocytes (SN2) induced stromal (Balb/c 3T3) and endothelial (HUVEC) cells to proliferate, which shows that both HB-EGF and the evaluated supernatants share angiogenic potential. The supernatant-associated angiogenic signals were inhibited by $100 \mu \mathrm{g} / \mathrm{mL}$ anti-HB-EGF neutralising Abs $(p<0.05)$. (B) HB-EGF induced proliferation and anti-apoptotic effects $(p<0.05)$ in HeLa (blue) and DLD-1 (red) cells. Cultures were performed in serum free medium in the absence $(\Delta)$ or presence $(\square)$ of $25 \mathrm{ng} / \mathrm{mL}$ HB-EGF. Proliferation was evaluated by an MTT assay after 24, 48 and 72 hours in culture. Apoptosis was evaluated at 72 hours by the detection of internucleosomal DNA fragmentation by a specific ELISA. The ratio between absorbance of untreated and treated cells (enrichment factor, EF) was used as an index of rescue from apoptosis due to serum deprivation. The means \pm SD of 5 experiments are depicted.

Moreover, the metastatic colon cancer cells stained positive for HER4 (Figure 1), through which HB-EGF exerts powerful chemotactic activity [19]. Thus, HB-EGF can induce cancer cell chemotaxis and proliferation as well as microenvironment-targeted angiogenic signals. Finally, Figure 6B shows that HB-EGF conferred upon HeLa and DLD-1 cells both proliferative and antiapoptotic signals; these latter signals clearly emerged under starvation conditions, as indicated by the statistically significant reduction in mono/oligonucleosomes released into the cytoplasm.

\section{CXCL12 and HB-EGF induce cancer cells to synthetise and release $\mathrm{GM}-\mathrm{CSF}$}

In addition, when HeLa and DLD-1 cancer cells were stimulated with $200 \mathrm{ng} / \mathrm{mL}$ CXCL12 and/or $25 \mathrm{ng} / \mathrm{mL}$ HB-EGF, GM-CSF proteins were detected by immunocytochemistry after 24 hours and new GM-CSF transcripts (as assessed by RT-PCR) appeared after 2 hours (Figure 7A, B). Conditioned medium obtained from cancer cells contained GM-CSF (Figure 8A) and induced HB-EGF expression in, and release from, mononuclear phagocytes (Figures 7C; 8B). Inhibitory anti-GM-CSF mAbs significantly reduced the production of HB-EGF (Figure 8B). Thus, CXCL12 and HB-EGF induced GMCSF expression in HeLa and DLD-1 cancer cells.

\section{Paracrine loop activated by CXCL12}

As described above, CXCL12 was shown to prompt mononuclear phagocytes and cancer cells to release HB-EGF and GM-CSF, respectively. On the other hand, we have previous evidence showing that GM-CSF is a strong inducer of HB-EGF expression in mononuclear phagocytes $[19,20]$. If HB-EGF released by mononuclear phagocytes can trigger the production of GM-CSF in cancer cells, a possible GM-CSF/HB-EGF paracrine loop may exist that is initially activated by CXCL12. Thus, we tested (i) HeLa and DLD-1 cancer cells for the production of GM-CSF upon HB-EGF stimulation and (ii) mononuclear phagocytes for the production of HB-EGF upon GM-CSF stimulation. This choice was based on the known differential receptor expression in mononuclear phagocytes, as opposed to cancer cells, which are usually negative for the GM-CSF receptor. Figure 7 depicts the experiments suggesting that a paracrine loop exists between Mø and HeLa or DLD-1 cancer cells. When these cancer cells were stimulated with $200 \mathrm{ng} / \mathrm{mL}$ CXCL12 and/or $25 \mathrm{ng} / \mathrm{mL}$ HB-EGF, they produced and released GM-CSF (Figures 7A, B; $8 \mathrm{~A})$. When mononuclear phagocytes were stimulated with CXCL12 and/or $25 \mathrm{ng} / \mathrm{mL}$ GM-CSF, they produced and released HB-EGF (Figures 2; 7B, C, D; 8B). HB-EGF mRNA transcripts and membrane protein levels were increased after 2 hours (Figures 2B; 7B) and after 24 hours of stimulation (Figures $2 \mathrm{~A}, \mathrm{C} ; 7 \mathrm{C}, \mathrm{D} ; 8 \mathrm{~B}$ ). These results were reproduced by the addition of conditioned medium from mononuclear phagocytes to cancer cells and vice versa (Figures 7A, C; 8). Inhibitory anti-HBEGF and anti-GM-CSF Abs significantly reduced the production of GM-CSF by cancer cells (Figure 8A) and HB-EGF by mononuclear phagocytes (Figure $8 \mathrm{~B}$ ), respectively. Thus, a paracrine loop may exist between mononuclear phagocytes and HeLa or DLD-1 cancer cells, as exemplified in Figure 7E. CXCL12 seems to act as an additive or synergistic agent in this positive feedback loop. The expression of these molecules as found in patient biopsy samples (Figure 1) is in line with and corroborates our findings in vitro. 


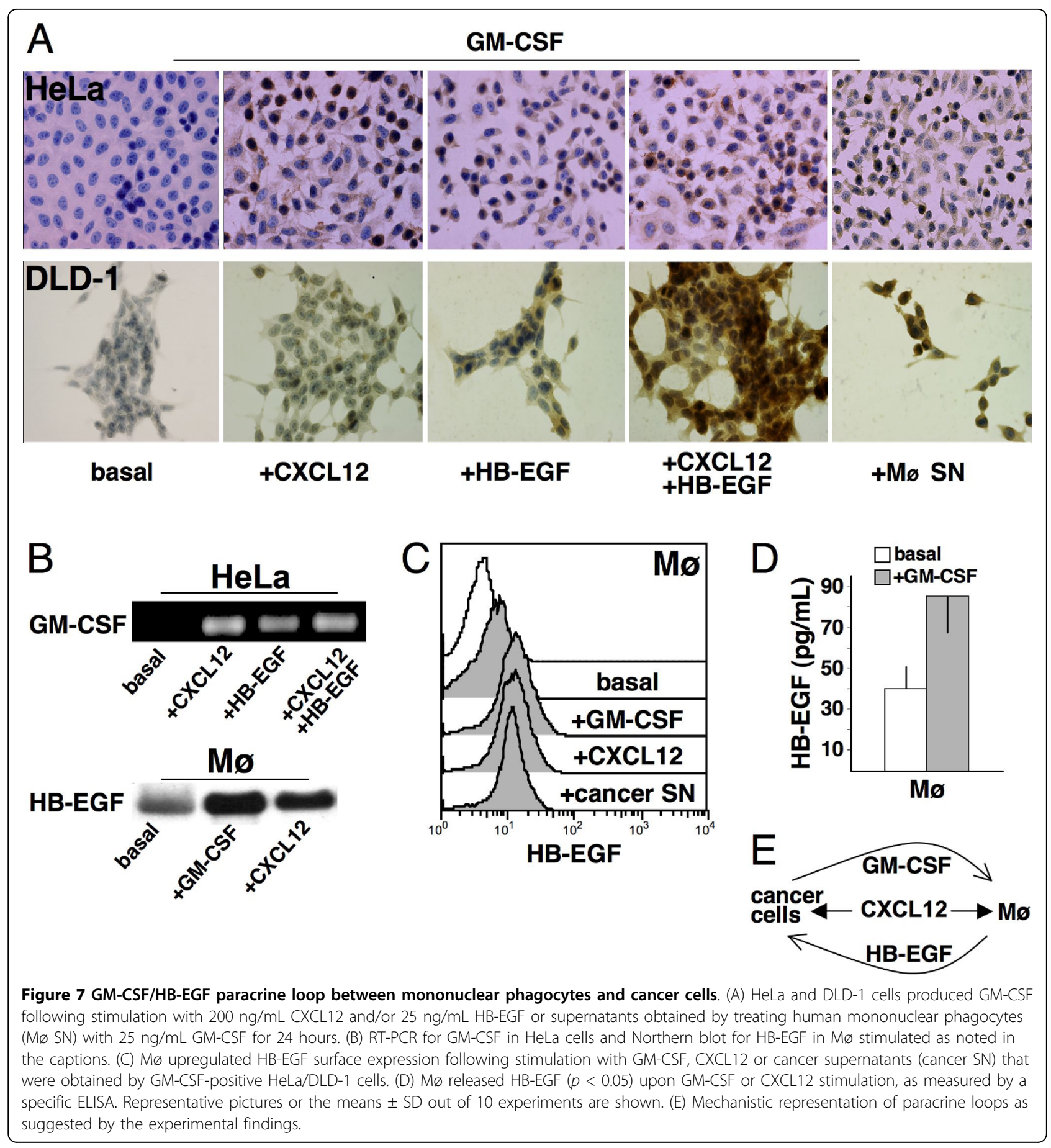

Blockade of GM-CSF in cancer cells

To further test the GM-CSF/HB-EGF loop between cancer cells and macrophages, we established a siRNA sequence targeted against GM-CSF. This siRNA efficiently blocked GM-CSF induction and release in HeLa and DLD-1 cells in response to both HB-EGF (Figure 9A) and conditioned medium from mononuclear phagocytes (data not shown). Similarly, inhibitory anti-
HB-EGF Abs significantly reduced the production of GM-CSF by cancer cells (Figure 8A). Therefore, HBEGF genuinely and specifically induced GM-CSF expression in these cells. The supernatant from silenced cancer cells lost the ability to upregulate HB-EGF in mononuclear phagocytes (Figure 9B) and inhibitory anti-GM-CSF Abs blocked the induction of HB-EGF (Figure 8B), showing that the upregulation was specifically due to 


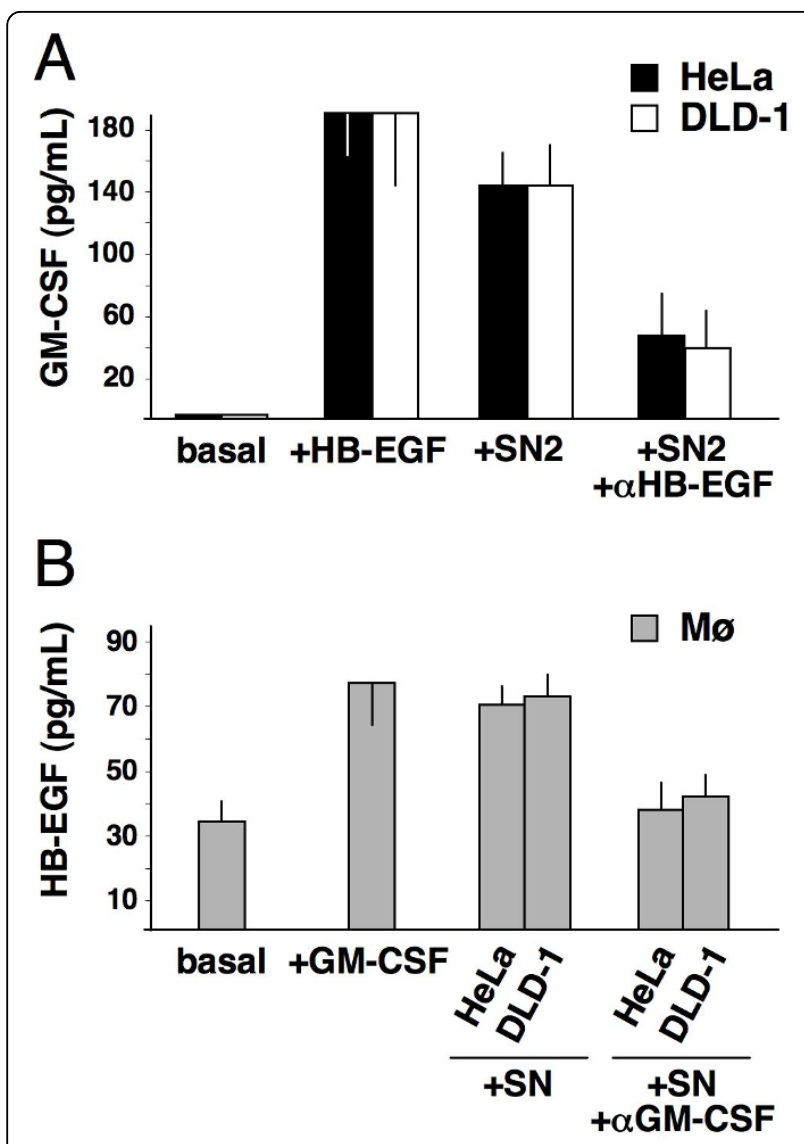

Figure $8 \mathrm{GM}-\mathrm{CSF}$ and HB-EGF release from cancer cells and mononuclear phagocytes. ELISA analysis (see Methods section) revealed that GM-CSF and HB-EGF were barely detectable under basal conditions in supernatants from HeLa/DLD-1 cells or mononuclear phagocytes, respectively, but accumulated 24 hours after stimulation. (A) Stimulation of HeLa/DLD-1 with $25 \mathrm{ng} / \mathrm{mL} \mathrm{HB}-$ EGF or supernatant from mononuclear phagocytes (SN2) induced GM-CSF release into supernatants. $100 \mu \mathrm{g} / \mathrm{mL}$ anti-HB-EGF blocking Abs reduced the supernatant-dependent release $(p<0.05)$. (B) Stimulation of mononuclear phagocytes with $25 \mathrm{ng} / \mathrm{mL}$ GM-CSF or supernatant from GM-CSF-positive cancer cells (SN) led to the accumulation of HB-EGF in supernatants. $100 \mu \mathrm{g} / \mathrm{mL}$ anti-GM-CSF neutralising Abs suppressed the supernatant-dependent release $(p<$ 0.05). The means \pm SD out of 10 experiments are depicted.

GM-CSF. Finally, mononuclear phagocytes treated with supernatants from GM-CSF-silenced cancer cells lost the ability to induce GM-CSF in non-silenced cancer cells (Figure 9C). Thus, GM-CSF silencing data complement the ligand-blocking experiments obtained with inhibitory Abs, and strengthen our experimental evidence supporting the existence of an activated GMCSF/HB-EGF loop between cancer cells and mononuclear phagocytes. When available, HB-EGF specifically stimulates cancer cells to produce GM-CSF, and the reciprocal availability of the two factors activates a positive feedback loop between them (Figure 7E).

\section{Discussion}

The current study defines a novel mechanism whereby CXCL12 redirects macrophages to promote a microenvironment that is suitable for cancer survival via a GMCSF/HB-EGF paracrine loop. To our knowledge, there are no other studies showing that human mononuclear phagocytes release and up-regulate HB-EGF, while cancer cells release and upregulate GM-CSF, when stimulated with CXCL12.

By evaluating histological samples from human colon cancer metastases in the liver, we observed that numerous HB-EGF/CXCR4-positive macrophages, which expressed both the M1 CXCL10 and the M2 CD163 markers, indicating a mixed M1/M2 microenvironment, infiltrated metastatic cancer cells. These in turn were positive for CXCR4, CXCL12, GM-CSF and HER1 (Figure 1). We then validated the mutual interactions associated with this repertoire of molecules in standard and transwell experiments performed on human mononuclear phagocytes and HeLa and DLD-1 cancer cell lines, expressing the same molecules in the same cellular distribution as macrophages and cancer in biopsy samples.

CXCL12 and GM-CSF induced mononuclear phagocytes to synthetise and release HB-EGF. Northern blotting of RNA from kinetic experiments revealed that maximal expression of HB-EGF mRNA occurred between 2 and 24 hours after CXCL12- or GM-CSF-dependent induction, leading to an increase in membrane HB-EGF molecule density (Figures 2; 7B, C). In transwell experiments, CXCL12-stimulated mononuclear phagocytes released HB-EGF that caused the phosphorylation of HER1 in HeLa and DLD-1 target cells (Figure 4B). Cell-free supernatants from CXCL12-treated mononuclear phagocytes induced HER1 phosphorylation followed by cellular proliferation in either HeLa or DLD-1 cells, an effect that was inhibited by anti-HB-EGF neutralising Abs (Figure 5).

Stimulation with CXCL12, HB-EGF or both induced GM-CSF transcripts in HeLa and DLD-1 cells. At 24 hours, immunocytochemistry revealed clear-cut staining for GM-CSF in both cell lines (Figure 7A). Their conditioned medium contained GM-CSF that induced Mø to produce HB-EGF (Figures 7C; 8B). Conversely, mononuclear phagocytes conditioned medium contained HBEGF that induced cancer cells to produce GM-CSF (Figures 7A; 8A). These effects were largely counteracted by the addition of specific neutralising Abs (Figure 8) or by GM-CSF silencing (Figure 9). In conclusion, CXCL12 induced HB-EGF in mononuclear phagocytes and GM-CSF in HeLa and DLD-1 cancer cells, activating or enhancing a GM-CSF/HB-EGF paracrine loop.

Thus, we have evidence for a specific pathway of activation in mononuclear phagocytes (CXCL12-stimulated $\mathrm{Mø}$ release of $\mathrm{HB}-\mathrm{EGF}$ ) that may match the specific 


\section{GM-CSF}
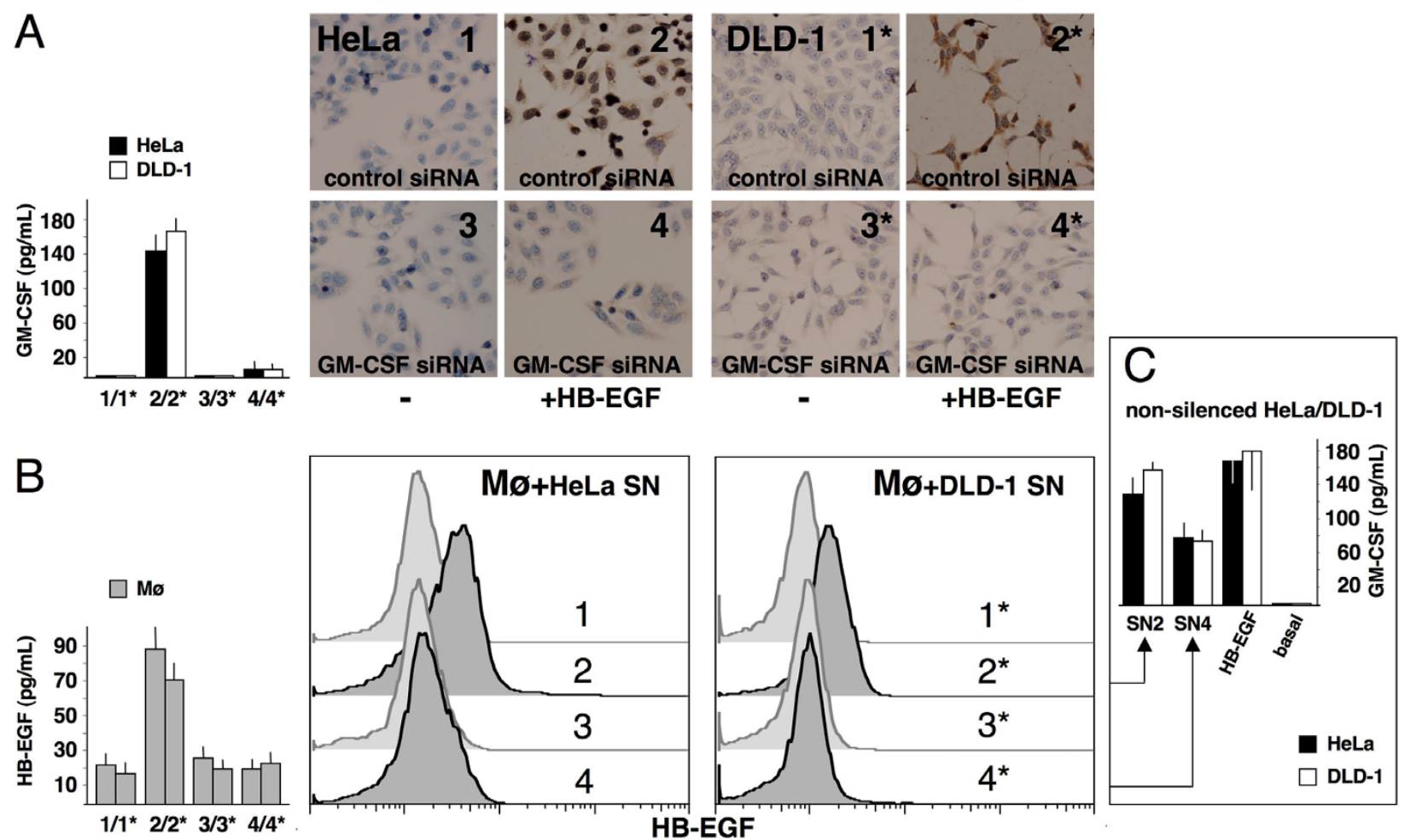

Figure 9 Knockdown of GM-CSF protein levels after siRNA application in cancer cells. HeLa/DLD-1 cells were transfected with control siRNA $\left(1 / 1^{*}, 2 / 2^{*}\right)$ or GM-CSF siRNA $\left(3 / 3^{*}, 4 / 4^{*}\right)$ and cultured in the absence or presence of $25 \mathrm{ng} / \mathrm{mL}$ HB-EGF. The numbers indicate the culture conditions and the corresponding supernatants (SN) used for ELISA or cell stimulation. (A) Blockade of GM-CSF production in cultures of HeLa/ DLD-1 cells transfected with GM-CSF siRNA was confirmed by immunocytochemistry (2/2* vs. 4/4*) and ELISA (left side; $2 / 2^{*}$ vs. $4 / 4^{*}, p<0.05$ ). (B) SN from GM-CSF-silenced HeLa/DLD-1 did not induce HB-EGF expression in mononuclear phagocytes (Mø), as revealed by flow cytometry (2/ $2^{*}$ vs. $4 / 4^{*}$ ) and ELISA (left side; $2 / 2^{*}$ vs. $4 / 4^{*}, p<0.05$ ). (C) Mø stimulated with SN from GM-CSF-silenced HeLa/DLD-1 cells released SN less effective at inducing GM-CSF in non-silenced cancer cells, as determined by ELISA (see Methods section; SN2 vs. SN4, $p<0.05$ ). Representative pictures or the means \pm SD out of 5 experiments are shown.

biological properties of some cancers (HeLa, DLD-1 and metastatic colon cancer). We have also documented a specific pathway of activation in cancer cells (CXCL12/ HB-EGF-stimulated cancer cell release of GM-CSF) that may match the specific biological properties of mononuclear phagocytes. This interplay between mononuclear phagocytes and cancer cells may lead to an inflammatory environment that favours rather than inhibits tumour growth. Furthermore, both macrophages and cancer cells were activated upon CXCL12 stimulation in liver biopsies (Figure 1), though we could not conclusively establish whether cancer cells produced their own CXCL12 or merely internalized CXCL12, produced by stromal cells. Other studies have demonstrated that CXCL12 transactivates HER2 in breast cancer cells [25], enhancing the expression of CXCR4 and favouring metastases [11]. In our work, CXCL12 has been shown to transactivate HER1 and induce GM-CSF. The latter is a specific inducer of HB-EGF, which in turn binds to HER1. HB-EGF acts as a chemotactic, pro-growth and anti-apoptotic factor in cancer cells, and plays a role as angiogenic factor by inducing endothelial cells and fibroblasts to proliferate (Figure 6). It also promotes angiogenesis by induction of VEGF [20]. In general, HBEGF is a powerful inducer of fibroblast activities $[17,19,20]$ that are involved in orchestrating inflammation and promoting tumour growth, angiogenesis and recruitment of macrophages and cancer cells [7].

Therefore, the CXCL12 receptors, CXCR4 and CXCR7, should be thought of as a node that connects multiple loops [26-30], including the highly important EGF/HER loops [13], linking cancer (oncogenes) and inflammation [5]. Based on our previous demonstration of the role of HER1 in the regulation of mesenchymal stem cell proliferation and differentiation [16], as well as on some general models $[5,31,32]$, we speculate that the crosstalk between CXCL12/CXCR4 and HB-EGF/HERs may contribute to the balance between the HER1dependent cellular responses of differentiation and selfrenewal [31-34]. 


\section{Hypothesis}

This study provides evidence that CXCL12 partecipates in the selective production of cytokines, leading to a GM-CSF/HB-EGF paracrine loop that may favour neoplastic growth. CXCL12 has chemotactic activity towards cancer and immune cells; in both cell types, it induces cytokines that retain pro-tumour activity and modulate the stromal component $[7,16]$, contributing to a tumour-permissive microenvironment. Therefore, CXCL12 signalling may provide a unifying basis for better understanding the complex relationships between cancer and inflammatory cells in terms of receptor crosstalk. For instance, the involvement of mixed M1/ M2, GM-CSF-stimulated macrophages in a tumourpromoting loop challenges the view of tumour-permissive macrophages as polarized M2 mononuclear phagocytes and hints at contexts in which pro-inflammatory microenvironments may allow effective tumour-promoting activities through mediators such as GM-CSF and HB-EGF. These mediators, indeed, seem to play a role that favours both cancer and a shift towards a M1polarized microenvironment. Eventually, such an understanding could contribute to the development of tools to interfere with recognised pathogenic signals [35].

\section{Acknowledgements}

This work was supported by grants from AIRC, Milan (Italy); from the Venetian Institute of Oncology (IOV), Padua (Italy); and from the Berlucchi Foundation, Brescia (Italy).

\section{Author details}

'Department of Medicine, Section of Hematology, University of Verona, Verona, Italy. ${ }^{2}$ Department of Pathology and Diagnostics, Section of Pathological Anatomy, University of Verona, Verona, Italy. ${ }^{3}$ Proteomics and Metabolomics Unit, Institute for Biomedical Technologies, CNR, Milan, Italy. ${ }^{4}$ Department of Experimental Biomedical Sciences, University of Padua, Padua, Italy.

\section{Authors' contributions}

$A R$ and MG performed the research, analysed the data, and performed statistical analyses; $A Z, E D, P M$ and $M B$ performed the research and contributed vital reagents and analytical tools; MK, GP contributed criticism; FV designed the research, analysed and interpreted data, and wrote the paper; all authors checked the final version of the manuscript.

\section{Competing interests}

The authors declare that they have no competing interests.

Received: 19 April 2010 Accepted: 14 October 2010 Published: 14 October 2010

\section{References}

1. Farinha P, Masoudi H, Skinnider BF, Shumansky K, Spinelli JJ, Gill K, Klasa R, Voss N, Connors JM, Gascoyne RD: Analysis of multiple biomarkers shows that lymphoma-associated macrophage (LAM) content is an independent predictor of survival in follicular lymphoma (FL). Blood 2005, 106:2169-2174

2. Dave SS, Wright G, Tan B, Rosenwald A, Gascoyne RD, Chan WC, Fisher Rl, Braziel RM, Rimsza LM, Grogan TM, Miller TP, LeBlanc M, Greiner TC, Weisenburger DD, Lynch JC, Vose J, Armitage JO, Smeland EB, Kvaloy S, Holte H, Delabie J, Connors JM, Lansdorp PM, Ouyang Q, Lister TA,
Davies AJ, Norton AJ, Muller-Hermelink HK, Ott G, Campo E, Montserrat E, Wilson WH, Jaffe ES, Simon R, Yang L, Powell J, Zhao H, Goldschmidt N, Chiorazzi M, Staudt LM: Prediction of survival in follicular lymphoma based on molecular features of tumor-infiltrating immune cells. N Engl J Med 2004, 351:2159-2169.

3. Steidl C, Lee T, Shah SP, Farinha P, Han G, Nayar T, Delaney A, Jones SJ, lqbal J, Weisenburger DD, Bast MA, Rosenwald A, Muller-Hermelink HK, Rimsza LM, Campo E, Delabie J, Braziel RM, Cook JR, Tubbs RR, Jaffe ES, Lenz G, Connors JM, Staudt LM, Chan WC, Gascoyne RD: Tumor-associated macrophages and survival in classic Hodgkin's lymphoma. N Engl J Med 2010, 362:875-885.

4. Biswas SK, Gangi L, Paul S, Schioppa T, Saccani A, Sironi M, Bottazzi B, Doni A, Vincenzo B, Pasqualini F, Vago L, Nebuloni M, Mantovani A, Sica A: $A$ distinct and unique transcriptional program expressed by tumorassociated macrophages (defective NF-kappaB and enhanced IRF-3/ STAT1 activation). Blood 2006, 107:2112-2122.

5. Mantovani A, Allavena P, Sica A, Balkwill F: Cancer-related inflammation. Nature 2008, 454:436-444.

6. Ramasamy R, Fazekasova H, Lam EW, Soeiro I, Lombardi G, Dazzi F: Mesenchymal stem cells inhibit dendritic cell differentiation and function by preventing entry into the cell cycle. Transplantation 2007, 83:71-76.

7. Mantovani A: La mala educación of tumor-associated macrophages: diverse pathways and new players. Cancer Cell 2010, 17:111-112.

8. Goswami S, Sahai E, Wyckoff JB, Cammer M, Cox D, Pixley FJ, Stanley ER, Segall JE, Condeelis JS: Macrophages promote the invasion of breast carcinoma cells via a colony-stimulating factor-1/epidermal growth factor paracrine loop. Cancer Res 2005, 65:5278-5283.

9. Nahrendorf M, Swirski FK, Aikawa E, Stangenberg L, Wurdinger T, Figueiredo $J$, Libby P, Weissleder R, Pittet MJ: The healing myocardium sequentially mobilizes two monocyte subsets with divergent and complementary functions. J Exp Med 2007, 204:3037-3047.

10. Müller A, Homey B, Soto H, Ge N, Catron D, Buchanan ME, McClanahan T, Murphy E, Yuan W, Wagner SN, Barrera JL, Mohar A, Verástegui E, Zlotnik A: Involvement of chemokine receptors in breast cancer metastasis. Nature 2001, 410:50-56

11. Li YM, Pan Y, Wei Y, Cheng X, Zhou BP, Tan M, Zhou X, Xia W, Hortobagyi GN, Yu D, Hung MC: Upregulation of CXCR4 is essential for HER2-mediated tumor metastasis. Cancer Cell 2004, 6:459-469.

12. Thelen M, Thelen S: CXCR7, CXCR4 and CXCL12: An eccentric trio? Neuroimmunol 2008, 198:9-13.

13. Shepard HM, Brdlik CM, Schreiber H: Signal integration: a framework for understanding the efficacy of therapeutics targeting the human EGFR family. J Clin Invest 2008, 118:3674-3681.

14. Daub H, Weiss FU, Wallasch C, Ullrich A: Role of transactivation of the EGF receptor in signalling by G-protein-coupled receptors. Nature 1996, 379:557-560.

15. Lefkowitz RJ: Seven transmembrane receptors: something old, something new. Acta Physiol (Oxf) 2007, 190:9-19.

16. Krampera M, Pasini A, Rigo A, Scupoli MT, Tecchio C, Malpeli G, Scarpa A, Dazzi F, Pizzolo G, Vinante F: HB-EGF/HER1 signaling in bone marrow mesenchymal stem cells: inducing cell expansion and reversibly preventing multilineage differentiation. Blood 2005, 106:59-66.

17. Miyamoto S, Yagi H, Yotsumoto F, Kawarabayashi T, Mekada E: Heparinbinding epidermal growth factor-like growth factor as a novel targeting molecule for cancer therapy. Cancer Sci 2006, 97:341-347.

18. Steube KG, Meyer C, Drexler HG: Secretion of functional hematopoietic growth factors by human carcinoma cell lines. Int J Cancer 1998, 78:120-124.

19. Vinante F, Rigo A, Papini E, Cassatella MA, Pizzolo G: Heparin-binding epidermal growth factor-like growth factor/diphtheria toxin receptor expression by acute myeloid leukemia cells. Blood 1999, 93:1715-1723.

20. Vinante F, Marchi M, Rigo A, Scapini P, Pizzolo G, Cassatella MA: Granulocyte-macrophage colony-stimulating factor induces expression of heparin-binding epidermal growth factor-like growth factor/ diphtheria toxin receptor and sensitivity to diphtheria toxin in human neutrophils. Blood 1999, 94:3169-3177.

21. Cassatella MA, Bazzoni F, Flynn RM, Dusi S, Trinchieri G, Rossi F: Molecular basis of interferon-gamma and LPS enhancement of phagocyte respiratory burst capability. Studies on the gene expression of several NADPH oxidase components. J Biol Chem 1990, 265:2024-2026. 
22. Mauri PL, Benazzi L, Flohé L, Maiorino M, Pietta PG, Pilawa S, Roveri A, Ursini F: Versatility of selenium catalysis in PHGPx unraveled by LC/ESIMS/MS. Biol Chem 2003, 384:575-588.

23. Guo L, Kozlosky CJ, Ericsson LH, Daniel TO, Cerretti DP, Johnson RS: Studies of ligand-induced site-specific phosphorylation of epidermal growth factor receptor. J Am Soc Mass Spectrom 2003, 14:1022-1031.

24. Saito T, Okada S, Ohshima K, Yamada E, Sato M, Uehara Y, Shimizu H, Pessin JE, Mori M: Differential Activation of Epidermal Growth Factor (EGF) Receptor Downstream Signaling Pathways by Betacellulin and EGF. Endocrinology 2004, 145:4232-4243.

25. Cabioglu N, Summy J, Miller C, Parikh NU, Sahin AA, Tuzlali S, Pumiglia K, Gallico GE, Price JE: CXCL-12/stromal cell-derived factor-1alpha transactivates HER2-neu in breast cancer cells by a novel pathway involving Src kinase activation. Cancer Res 2005, 65:6493-6497.

26. Koizumi K, Hojo S, Akashi T, Yasumoto K, Saiki I: Chemokine receptors in cancer metastasis and cancer cell-derived chemokines in host immune response. Cancer Sci 2007, 98:1652-1658.

27. Montresor A, Bolomini-Vittori M, Simon SI, Rigo A, Vinante F, Laudanna C: Comparative analysis of normal versus CLL B-lymphocytes reveals patient-specific variability in signaling mechanisms controlling LFA-1 activation by chemokines. Cancer Res 2009, 69:9281-9290.

28. Vinante F, Rigo A, Scupoli MT, Pizzolo G: CD30 triggering by agonistic antibodies regulates CXCR4 expression and CXCL12 chemotactic activity in the cell line L540. Blood 2002, 99:52-60.

29. Burger JA, Kipps TJ: CXCR4: a key receptor in the crosstalk between tumor cells and their microenvironment. Blood 2006, 107:1761-1767.

30. Meijer J, Ogink J, Roos E: Effect of the chemokine receptor CXCR7 on proliferation of carcinoma cells in vitro and in vivo. Br J Cancer 2008, 99:1493-1501.

31. Corcoran KE, Trzaska KA, Fernandes H, Bryan M, Taborga M, Srinivas V, Packman K, Patel PS, Rameshwar P: Mesenchymal stem cells in early entry of breast cancer into bone marrow. PLOS ONE 2008, 3:e2563.

32. Zandstra PW, Lauffenburger DA, Eaves CJ: A ligand-receptor signaling threshold model of stem cell differentiation control: a biologically conserved mechanism applicable to hematopoiesis. Blood 2000, 96:1215-1222.

33. Moharita AL, Taborga M, Corcoran KE, Bryan M, Patel PS, Rameshwar P: SDF-1alpha regulation in breast cancer cells contacting bone marrow stroma is critical for normal hematopoiesis. Blood 2006, 108:3245-3252.

34. Kim S, Takahashi H, Lin WW, Descargues P, Grivennikov S, Kim Y, Luo JL, Karin M: Carcinoma-produced factors activate myeloid cells through TLR2 to stimulate metastasis. Nature 2009, 457:36-37.

35. Hachet-Haas M, Balabanian K, Rohmer F, Pons F, Franchet C, Lecat S, Chow KY, Dagher R, Gizzi P, Didier B, Lagane B, Kellenberger E, Bonnet D, Baleux F, Haiech J, Parmentier M, Frossard N, Arenzana-Seisdedos F, Hibert M, Galzi JL: Small Neutralizing Molecules to Inhibit Actions of the Chemokine CXCL12. J Biol Chem 2008, 283:23189-23199.

doi:10.1186/1476-4598-9-273

Cite this article as: Rigo et al: Macrophages may promote cancer growth via a GM-CSF/HB-EGF paracrine loop that is enhanced by CXCL12. Molecular Cancer 2010 9:273.

\section{Submit your next manuscript to BioMed Central and take full advantage of:}

- Convenient online submission

- Thorough peer review

- No space constraints or color figure charges

- Immediate publication on acceptance

- Inclusion in PubMed, CAS, Scopus and Google Scholar

- Research which is freely available for redistribution

Submit your manuscript at www.biomedcentral.com/submit
C Biomed Central 